\title{
Prevalence of SI and NSI among Nurses in Northern West Bank Hospitals / Palestine
}

\author{
Mariam Amer Al-Tell ${ }^{1}$, Bushra Jamal Almurr ${ }^{2}$ \\ ${ }^{1}$ Ph.D Community Health, Assistant Professor An-Najah National University \\ ${ }^{2}$ Public Health Student
}

\begin{abstract}
Introduction: Standard precautions defined as "a group of infection prevention practices that apply to all patients, regardless of suspected or confirmed diagnosis or presumed infection status". The aim of these precautions is prevention and or reduction of transmission of HAI, and in the same time, protection of Nurses from sharp injuries. Main objective: the main objective is to assess Prevalence of SI and NSI and related causes among Nurses in Northern West Bank Hospitals /Palestine. Method: a systemic random sample of (249) nurses was selected from Rafedia hospital, Alwatani hospital, Thabet Thabet hospital, Khalil Suleiman hospital and Darwish Nazzal hospital. Self administrated questionnaire was filled by participants, and data was analysis by using SPSS version 17. Results: the result showed that the prevalence of sharp injuries and needle stick injuries in previous 12 month were (66.8\%) and (46.4\%) respectively. Conclusion and Recommendations: standard precaution is basic level of infection control precaution . However , the vast majority of participants in this study didn't always follow it. So more training program on infection control and more concentration on standard precaution by educational program and regular lectures must be given to nurses in order to improve their knowledge and practice of SP measures.
\end{abstract}

Keywords: Stick Injury, Needle Stick Injury, Prevalence, Nurses

\section{Introduction}

Health-care associated infection (HAI) referred to as nosocomial infection and hospital acquired infection, is defined by Center of Disease Control and Prevention (CDC) as an "infection caused by a wide variety of common and unusual bacteria, fungi, and viruses during the course of receiving medical care"1 . It either occurs while patients receive care or may develop after discharge. It also involves occupation infection among staff. HAI can also be defined as an "infection occurring in patients during the process of care in a hospital or health care facility which was not present or incubating at the time of admission. This includes infection acquired in the hospital, but appearing after discharge and also occupational infections among staff or facility"2.

HAI is considered an important public health problem². Globally, hundreds of millions of patients are infected by HAI every year in both developed and developing countries. According to WHO, its prevalence in developed countries varied between $3.5 \%$ and $12 \%$, while in developing countries it varied between $5.7 \%$ and $19.1 \%{ }^{3}$. The highest occurrence of HAI were in acute surgical, orthopedic wards and Intensive Care Unit ${ }^{2}$. The prevalence rate of ICUacquired infection in high-income countries was $30 \%$, while in middle and low- income countries, it was at least 2-3 times higher than that in high -income countries ${ }^{3,4}$

The consequences of HAI at patients' level imply more suffering, more complications, more treatments, and increase in hospitalization periods.

\subsection{Health-associated infections among health care workers /nurses}

HAI can affect both patients and health-care workers. It involves occupational infections among nurses. Due to the nature of their occupations, the major occupational hazard is the transmission of blood-borne disease such as hepatitis B and AIDS by being exposed to injuries caused by contaminated sharp objects such as scalpels and broken glass and needle stick ${ }^{1}$. Nurses can be infected by HAIs while dealing with patients or providing them with health treatment. They can play a role in the widespread of infections. The mode of transmission depends on many factors such as immunity of HCW and amount of blood transferred during injuries ${ }^{1}$. According to WHO, nearly three million HCW are exposed to percutaneous blood borne pathogens each year worldwide; 2 million of those were exposed to HBV ,0.9 million to HCV and 170, 000 to HIV.

These sharp injuries resulted in 15,000 HCV, 70,000 HBV and 500 HIV infections. About $90 \%$ of these events happened in the developing countries ${ }^{2}$. The infectious agent is transmitted to nurses mainly via droplet: direct contact or contact with inanimate contaminated objects by infectious material. The risk of transmission of infectious agents would increase if infection control practice and standard precautions were not applied $^{5}$

As per ${ }^{3}$. The Solutions of this problem include the following:

- Encouragement of the reporting and surveillance system.

- Improvement of education and training of nurses in applying safety precaution.

- Implementation and application of standard precaution measures.

\subsection{Sharp Injuries (SI)}

SI are defined as "an exposure to event occurring when any sharp penetrates the skin" ${ }^{3}$. These include needles, scalpels, broken glass, and other sharps. This term is interchangeable with percutaneous injury. It is considered a serious hazard in hospitals because it may allow the contaminated blood that 


\section{International Journal of Science and Research (IJSR) \\ ISSN (Online): 2319-7064 \\ Index Copernicus Value (2013): 6.14 | Impact Factor (2014): 5.611}

has pathogen to be in contact with nurses. SI and NSI lead to infection. They expose nurses to blood- borne pathogens which mean " pathogenic microorganisms that are present in human blood and can cause disease in humans. These pathogens include, but are not limited to, hepatitis B virus"3 - SI and NSI are considered a major source of Hepatitis C Virus (HCV) infection among HCWs. Nearly (39\%) of cases of $\mathrm{HCV}$ that occurred worldwide happened among HCWs, while hepatitis B virus (HBV) formed $(37 \%)^{6}$. Furthermore, needle stick injuries can transmit more than twenty types of infections such as malaria, syphilis and herpes ${ }^{7}$.

SI and NSI are a problems that threaten nurses and form a significant risk in professional nursing. This is due to their daily activities which may expose nurses to NSI and SI. These activities or procedures include the following: recapping needle, suturing, placing intravenous line, drawing blood, failing to get rid of used needles in punctureresistant sharps containers, using needles or glass equipment to transfer body fluid between containers, disassembling needle or sharp device, giving injections to patients, filling injection, opening the lid of the injection and many others ${ }_{\mathbf{8}, 9}$. These tasks and activities of nurses in daily work may expose them to SI or NSI. Therefore, to prevent transmission of blood borne pathogens to nurses after being exposed to such injuries, they should immediately wash the wound with water and soap. On the other hand, squeezing the wounds is not recommended as this will not reduce the risk of bloodborne pathogen. In case of the splash of blood or body fluid touches the nose or the mouth or the skin, they must flush these splashes with water and in case of blood or body fluid comes in contact with the eye, they should irrigate eyes with clean water or saline. Then they should inform the supervisor about injury to begin a reporting system (incidence report). At the same time, they should test the source patient for hepatitis B, hepatitis C and AIDS. After that, infected nurses should receive the appropriate treatment, and post exposure prophylaxes (PEP) should be taken if the source patient was unknown or the source patients' test was positive ${ }^{7,10}$.

Sharp injuries and needle stick injuries are costly; these injuries have direct and indirect cost at the same time. The direct cost includes the cost of laboratory test of exposed nurses and source patient, in addition to the cost of treatment that may be required or post exposure prophylaxis. On the other hand, the indirect cost includes loss of nurses, loss of productivity, loss of time during reporting or taking of treatments and cost for replacing the infected nurses ${ }^{\mathbf{1 1}}$. According to CDC's estimation, there were nearly $(385,000)$ SI cases yearly among HCWs, and most reported cases occurred among nursing staff, but laboratory staff, physicians and other HCWs were also injured ${ }^{\mathbf{1 1}}$. Nearly half of SI were not reported; this was due to many reasons: lack of time to report, lack of knowledge of the reporting procedure, possibility of getting in trouble for having the exposure, belief the source patient was low for hepatitis B or hepatitis $\mathrm{C}$ or AIDS, and underestimation of the importance of reporting ${ }^{12,13,14}$. Reporting of NSI and SI is an important step, and it is essential to report such cases of injuries because it can protect injured nurses by ensuring right time for taking treatment or doing required test (or post-exposure follow up). Also reporting can help in obtaining data which can be used to assess the health of nurses and safety of surrounding workplace ${ }^{\mathbf{1 5 , 1 6}}$. Prevention of needle stick injuries and injuries from other sharps instruments is an important element of $\mathrm{SP}^{\mathbf{1 7}}$. Accordingly, care must be taken when using sharp objects or when cleaning the used one or when disposing of used needle and other sharp objects. The used needle and other sharp objects should be disposed of properly in Sharp Disposal Containers (or Box).

\subsection{Sharp Disposal Containers (or Box):}

Sharp objects must be disposed in separate containers in every hospital to prevent risk of transmission of infection. These containers are called sharp disposal containers and they must be puncture-resistant, liquid -proof, closed when not used and sealed and when (75\%) of them are filled. They should be put nearby work place and close to place where sharp is used. This would reduce the occurrence of recapping needles and needle-stick injuries that are associated with recapping ${ }^{18,5}$.

National Institute for Occupational Safety and Health 19 made a focus group to know elements needed for making sharp disposal containers safe. The elements were as follows:

1) Functionality: This means the containers should be puncture-resistant, liquid-proof, shape and size are suitable, closed well and low risk of incidence of injuries when closed.

2) Accessibility: This means containers should be easy to reach, put in visible place, and away from certain areas such as near doors or near light swatch.

3) Visibility: This means the containers should be clearly visible, and easy to see the amount that fills them.

4) Accommodation: This means containers should be easy to store and assemble, they don't need too much worker training, and have a flexible design.

\subsection{Conceptual Framework}

Nurses are often exposed to microorganisms, which can cause infections ${ }^{20,21}$. Although the simplicity of standard precautions, but compliance among nurses is law. Compliance of standard precaution can be influenced by many factors such as; lack of knowledge lack of equipments, individual, environmental, economic and social factors and others ${ }^{22}$ as shown in following figure: 


\section{International Journal of Science and Research (IJSR) \\ ISSN (Online): 2319-7064}

Index Copernicus Value (2013): 6.14 | Impact Factor (2014): 5.611

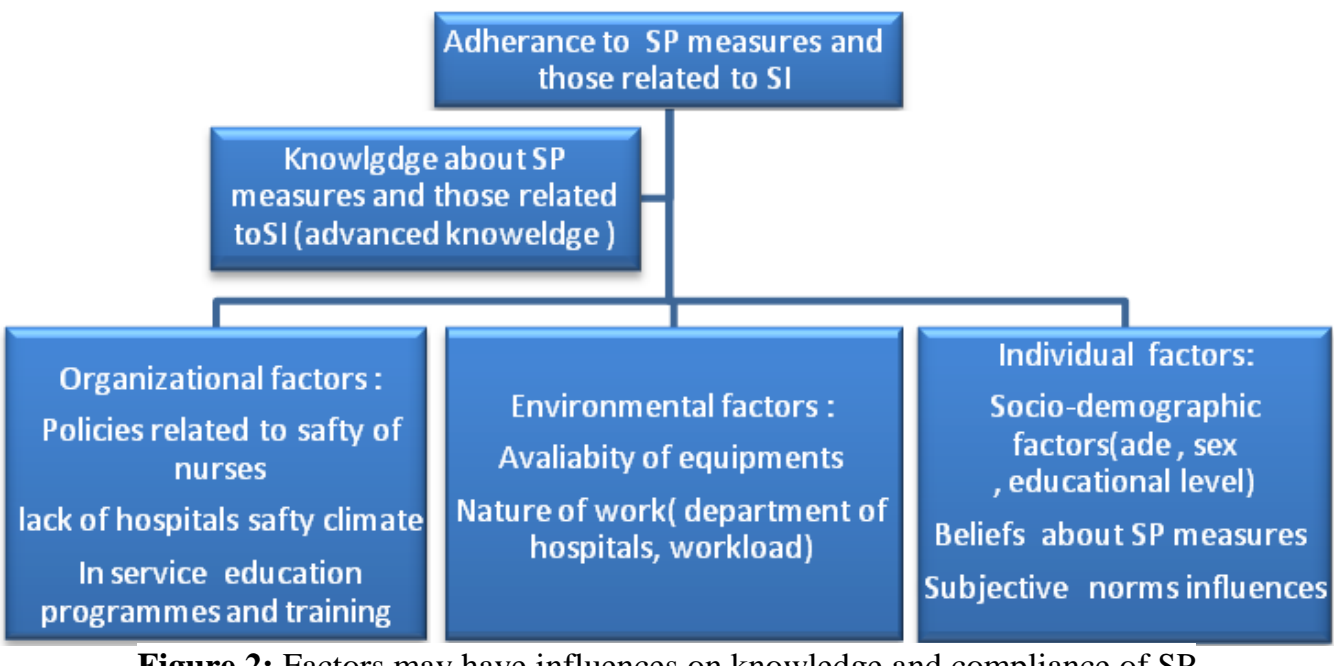

Figure 2: Factors may have influences on knowledge and compliance of SP

SP measures consider as a first-line approach to infection prevention and control in the hospital, and it is followed to break the link of cycle of infection and therapy prevent occurrence or transmission of infection ${ }^{\mathbf{1 0}}$.

Chain of Infection

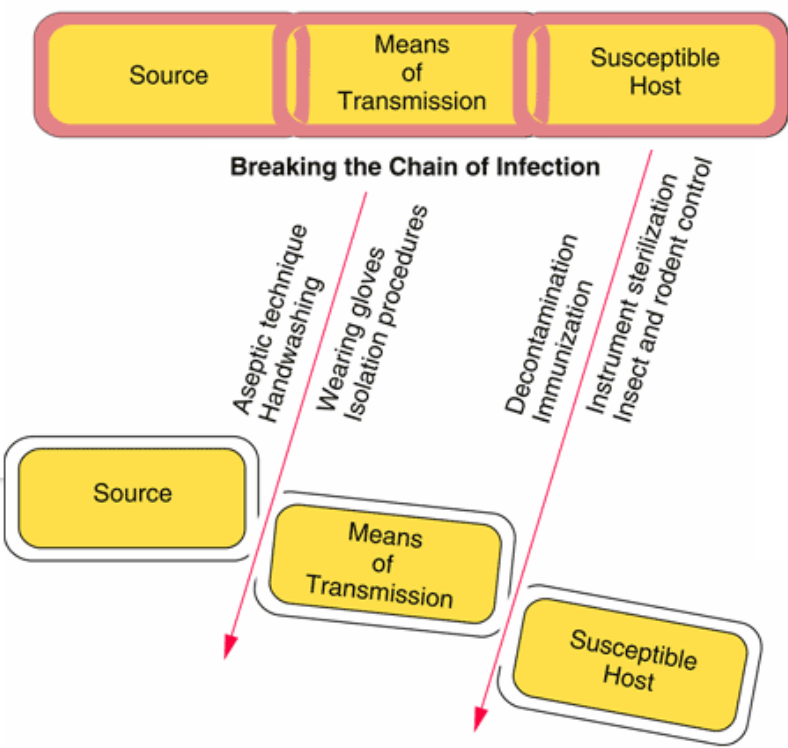

Figure 3: Cycle of infection (CDC,2007).

Because break the cycle of infection is the foundation of infection prevention. Therefore, nurses must have knowledge about each element of this cycle to know how infection occurs also measures and precaution that leading to break links of this cycle ${ }^{5}$. The following figure show example about breaking the chain of infection by SP

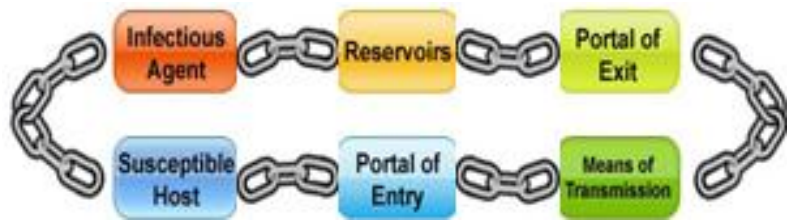

Figure 4: Braking the chain of infection(MCcALL ET AL.)

\subsection{Problem Statement}

Nurses get in contact with patients on a daily basis, so they are exposed to sharp injuries and many types of infections due to the nature of their occupation. It is important to follow standard precautions to reduce transmission of infections. In Palestine, despite of the availability of protocol for infection control in hospitals, it is applicable in varied degree from hospital to hospital. In addition, after reviewing documents from Palestinian Health Information Centre in $\mathrm{MOH}$, it doesn't have any statistics regarding nurses who have SI or who acquired infection during work. As an expected outcome, this study will highlight the size of problem of stick injuries among nurses during work. It will identify prevalence of NSI and SI among nurses Also it will identify the main related causes.

\subsection{Significance of the Study}

This research, the first of its kind to be done in governmental hospitals in West Bank, to assesses the prevalence of NSI and SI among nurses. Globally, many studies have been conducted about knowledge and practice of SP measures and those related to sharp injuries.

Safety of Nurses and patients is considered an important issue in controlling and limiting the transmission of infectious disease between nurses and patients. Following such standard precautions, which are easy and simple, would reduce the transmission of many types of contagious disease, thus reducing the economic burden of treating these diseases.

This study calculated SI and NSI among participants. It is important to know prevalence of SI and NSI because needle sticks and sharps injuries represent a significant hazard in professional nursing and exposure to blood and body fluid has been considered as part of nurses' job.

It is expected that this study will play an important role it expected to highlight the size of the problem of SI and NSI.

\subsection{Objectives}

Aim: to assess the prevalence of SI and NSI among nurses

\section{Specific Objectives}

1) To estimate the prevalence of sharp injuries and needle stick injuries among nurses in the target hospitals. 


\section{International Journal of Science and Research (IJSR) \\ ISSN (Online): 2319-7064 \\ Index Copernicus Value (2013): 6.14 | Impact Factor (2014): 5.611}

2) To identify the percentage of needles sticks as a result of sharp injuries.

3) To identify the main related causes of SI and NSI among nurses

\section{Research question}

- What is the prevalence rate of SI and NSI among the nurses

- What are the main related causes of SI/NSI

- What are the measures taken by hospitals regarding infection control to prevent injuries and their consequences

\section{Methodology}

\section{Study design:}

A cross-sectional study was used to predict the prevalence of NSI and the related causes among nurses

\section{Setting:}

The study was conducted at the governmental hospitals of Nablus, Jenin, Qalqilya and Tulkarm in the northern West Bank.

\section{Population of the study}

Based on MOH report of 2011, there were (547) nurses working in the five aforementioned hospitals.

\section{Sample and Sampling method:}

The calculated sample size was (249) nurses: (226) using the sample size calculator by Raosoft with a (95\%) confidence level, (5\%) error, and (50\%) response distribution + (10\%) drop out.

The systematic random technique was used; the number of nurses from each hospital was chosen, using the proportion method. And simple random method was used to select participant from each hospital.

\section{Inclusion Criteria}

- All nurses were registered in the aforementioned governmental hospitals.

\section{Exclusion Criteria}

- Participants who participated in the pilot study

- Nurse students

\subsection{Tool of Data Collection}

\section{Self- Administered Questionnaire}

The part of questionnaire about exposure to NSI and SI and measurement taken by hospital regarding infection control was developed on the basis of survey done by CDC. This survey is called Survey of Healthcare Personnel on Occupational Exposure to Blood and Body (CDC, 2005).

\section{Questionnaire consisted of three parts:}

The first part assessed the Socio-demographic data: this part included questions about age, gender, categories of nurses, department of hospital, years of experience, place of work.

The second part assessed exposures to needle stick injuries and sharp injury (it contained questions about times of NSI or SI in the past 12 months and causes that led to these injuries).

The third part covered measures taken by hospitals regarding infection control to prevent injuries and their consequences: (Questions about reporting of injuries, and causes of not reporting these injuries, place of sharp containers and vaccination of nurses against hepatitis B virus).

\section{Pilot Study}

A pilot study was conducted at 2 hospital: Rafidya and Thabet Thabet. Twenty five nurses were randomly selected to fill in a self- administered questionnaire in order to identify the problems that faced the participants, and the time taken by participants to fill in/out the questionnaire and the required modification.

\section{Validity and reliability of the test}

Validity of the questionnaire was tested as follows:

- The questionnaire was reviewed by two academic scholars with a experience in developing and administering questionnaire.

- A pre -test was conducted as a pilot study on twenty five nurses were randomly selected to fill in a selfadministered questionnaire

Reliability: Reliability of questionnaire was calculated by cronbach's alpha, it was 0.87 for the questions about Exposure to SI and NSI and 0.70 for those related to Measurement taken by hospital regarding infection control

\section{Ethical considerations}

Approval from Institutional Review Board (IRB) at AnNajah National University was obtained. In addition, an approval was obtained from the $\mathrm{MOH}$ and selected hospitals. Consent of participants was also obtained. And participants were given the right to withdraw at any time of study.

\section{Field work}

After the approval was obtained from $\mathrm{MOH}$ the pilot study was conducted. Data collection lasted from November 6 to December 29, 2012.

Data analysis and test used:

ll statistical analyses were conducted by using Statistical Package for Social Sciences (SPSS) version 17.0 for Windows.

\section{Limitation of the study}

First, potential reporting bias associated with the selfadministered questionnaire concern always existed about accuracy in these surveys. It was difficult to determine with certainty whether the responses reflected what nurses actually did. Specifically, compliance to control measures was based solely upon the subjective views of nurses with the possibility that they tended to over-report compliance. A more effective method of measuring compliance would be the direct observations of actual practice; in this study it was difficult to do so due to time limitation.

A second limitation was that the study took place in governmental hospitals. All other hospitals were not 


\section{International Journal of Science and Research (IJSR) \\ ISSN (Online): 2319-7064 \\ Index Copernicus Value (2013): 6.14 | Impact Factor (2014): 5.611}

included, and so the results can't be generalized among all the nurses working in the north of the West Bank.

Finally, and due to the high workload in governmental hospitals, some of the participants failed to complete the questionnaire in the first time while others forgot to fill it and a number of them had their questionnaires lost, so they were visited again and new copies were provided to them to fill.

\section{Results}

The prevalence of NSI

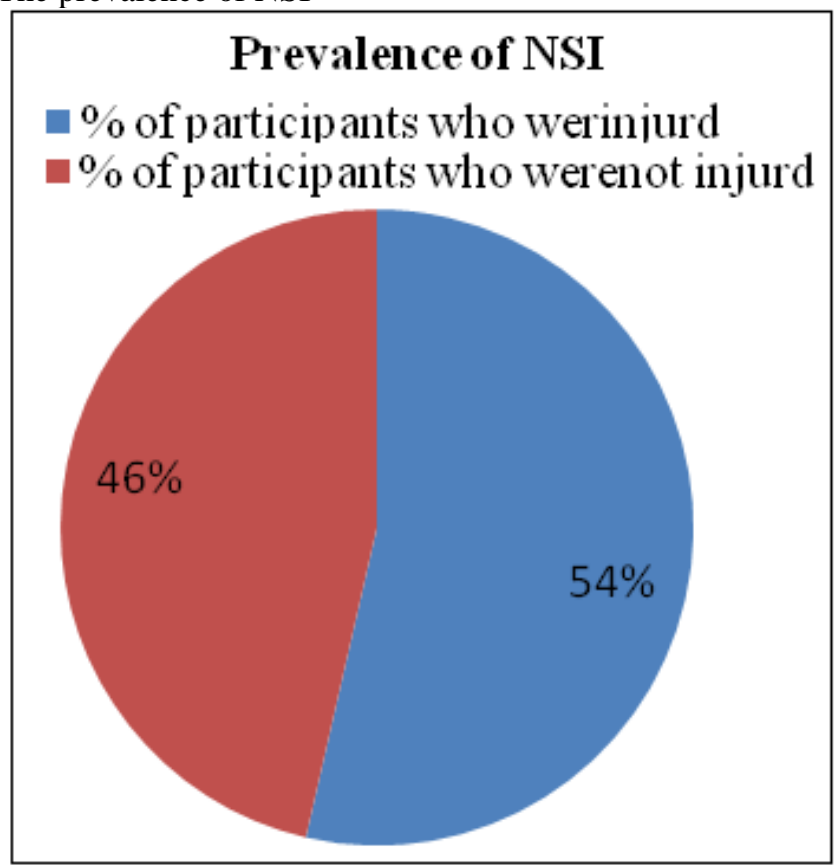

Figure 1: Distribution of participants according to exposure to NSI in the past 12 months

Figure (1) shows that in the past 12 months prior to the study,(46.4\%) of participants were exposed to NSI and (53.6\%) who were not exposed to them.

\section{Knowledge of participants about the usage of needle}

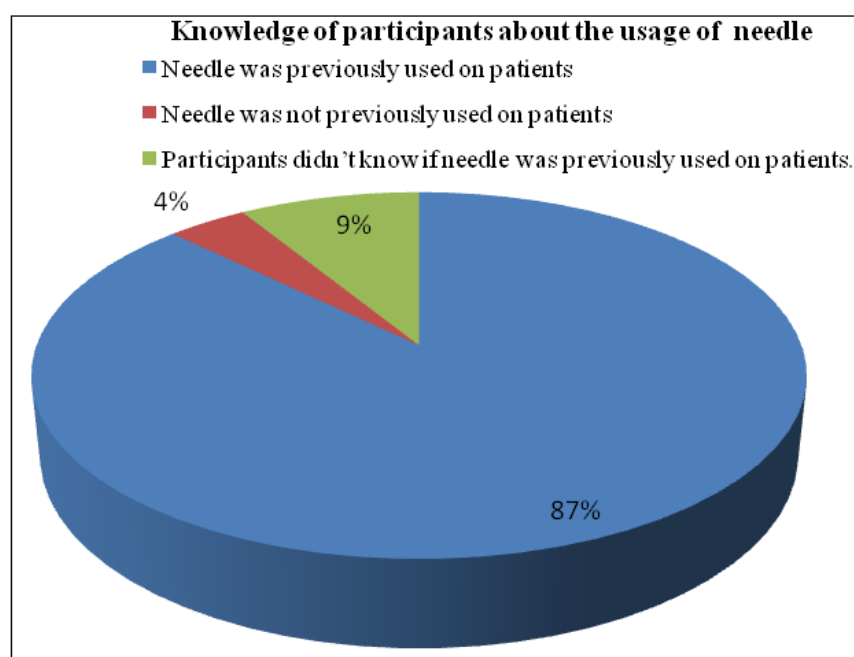

Figure 2: Distribution of injured participants by needles according to their knowledge of whether the needle was previously used on patients or not

Figure (2) shows the knowledge of participants about whether needle was used previously on patients before injuries had occurred. More than (87\%) of injured participants by needle reported that the needle was previously used on patients while only (3.9\%) of injured participants by needle reported that the needle was not previously used on patients. In contrast, (8.8\%) of injured participants by needle reported that they didn't know if needle was previously used or not on patients.

\section{Number of injuries in the past 12 months:}

The following table shows the numbers of SI and NSI that participants were exposed to during $12^{\text {th }}$ months before conducting the study.

Table 1: Distribution of participants according to number of injuries during $12^{\text {th }}$ months before conducting the study

\begin{tabular}{|c|c|c|c|c|}
\hline No. of SI/NSI during past 12 months & \multicolumn{2}{|c|}{ SI } & \multicolumn{2}{c|}{ NSI } \\
\hline & No & $\%$ & No & $\%$ \\
\hline 1 & 78 & 53 & 63 & 61.8 \\
\hline 2 & 51 & 34.7 & 28 & 27.5 \\
\hline 3 & 14 & 9.5 & 7 & 6.9 \\
\hline 4 & 2 & 1.4 & 3 & 2.9 \\
\hline 5 or more & 2 & 1.4 & 1 & 0.9 \\
\hline
\end{tabular}

Table (1) shows that (53\%) and (61.8\%) of participants were exposed once to SI and NSI respectively during $12^{\text {th }}$ months before conducting the study. In opposed, (34.7\%) of participants were exposed twice to SI and About (27.5\%) of them were exposed twice to NSI during $12^{\text {th }}$ months before conducting the study. It also showed that only (1.4\%) and $(0.9 \%)$ of participants were exposed to five and more SI and NSI during $12^{\text {th }}$ months before conducting the study respectively. 


\section{International Journal of Science and Research (IJSR) \\ ISSN (Online): 2319-7064}

Index Copernicus Value (2013): 6.14 | Impact Factor (2014): 5.611

\section{Distribution of Percentage of Participants regarding Causes of SI}

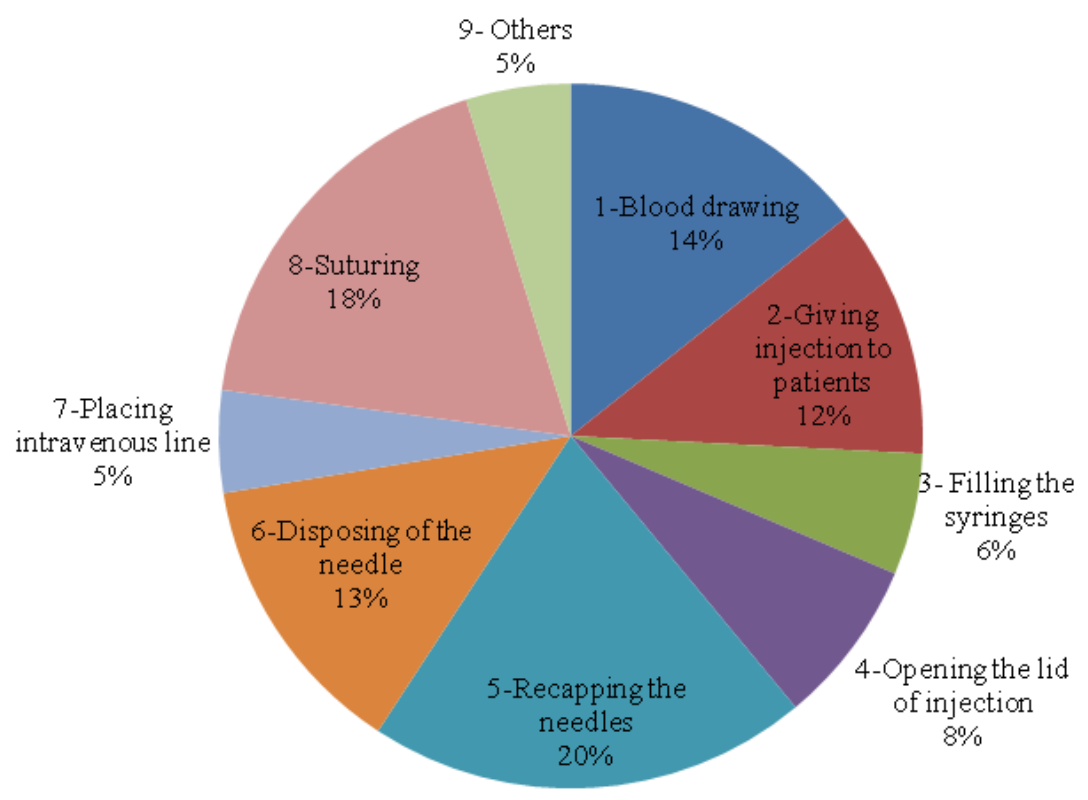

\section{Causes of Sharp Injuries:}

Figure (3) shows the causes of sharp injuries: $(20.2 \%)$ of injured participants were injured during recapping needle; (8.1\%) of injured participants were injured during suturing, (14.3\%) were injured during blood drawing; (13.2\%) were injured during needle disposal; (11.5\%) were injured during giving injections to patients and (4.8\%) of participants were injured due to other causes.

\section{Measures taken by hospitals regarding infection control:}

Table 2: Distribution of percentages of participants' knowledge about measures taken by hospitals regarding infection control

\begin{tabular}{|c|c|c|}
\hline \multicolumn{3}{|c|}{$\begin{array}{l}\text { Measures taken by hospitals regarding infection } \\
\text { control }\end{array}$} \\
\hline Item & No & $\%$ \\
\hline \multicolumn{3}{|l|}{$\begin{array}{l}\text { Numbers of completed reports about } \\
\text { sharp injuries }\end{array}$} \\
\hline 0 & 112 & 76.2 \\
\hline 1 & 29 & 19.7 \\
\hline 2 & 4 & 3.04 \\
\hline 3 and more & 2 & 1.06 \\
\hline \multicolumn{3}{|l|}{$\begin{array}{l}\text { 2- Reasons for not reporting the } \\
\text { injuries }\end{array}$} \\
\hline I did not have time to report & 12 & 10.7 \\
\hline I did not know the reporting procedure & 57 & 50.9 \\
\hline $\begin{array}{l}\text { I did not think it was important to } \\
\text { report }\end{array}$ & 23 & 20.5 \\
\hline $\begin{array}{l}\text { I thought I might be blamed or get in } \\
\text { trouble for having the exposure }\end{array}$ & 7 & 6.3 \\
\hline I was concerned about confidentiality & 2 & 1.8 \\
\hline $\begin{array}{l}\text { I thought the source patient had low } \\
\text { risk for HIV and/or hepatitis B or C }\end{array}$ & 5 & 4.4 \\
\hline $\begin{array}{l}\text { I thought there was a low risk for the } \\
\text { type of exposure for HIV and/or } \\
\text { hepatitis B or C }\end{array}$ & 4 & 3.6 \\
\hline others & 2 & 1.8 \\
\hline \multicolumn{3}{|c|}{$\begin{array}{l}\text { 3-Availability of protocol/ procedure for reporting the } \\
\text { injuries }\end{array}$} \\
\hline Yes & 101 & 45.9 \\
\hline No & 69 & 31.4 \\
\hline Don’t know & 50 & 22.7 \\
\hline
\end{tabular}

4-If yes (in previous points 4), are you familiar with how to report these exposures?

\begin{tabular}{|c|c|c|}
\hline Yes & 39 & $38.6^{*}$ \\
\hline No & 62 & 61.4 \\
\hline \multicolumn{3}{|c|}{$\begin{array}{l}\text { 5-Places where participants received care after getting } \\
\text { injured }\end{array}$} \\
\hline Employee Occupational Health & 13 & 8.8 \\
\hline Infection Control & 34 & 23.1 \\
\hline Emergency Room & 39 & 26.5 \\
\hline Personal Physician & 13 & 8.8 \\
\hline Outpatient Clinic & 2 & 1.4 \\
\hline Others & 4 & 2.8 \\
\hline I didn’t Receive Care & 42 & 28.6 \\
\hline \multicolumn{3}{|l|}{ 6-Place of Sharp Containers } \\
\hline Each Procedure Room & 88 & 40 \\
\hline Each Patient Room & 18 & 8.2 \\
\hline Medication Carts & 91 & 41.3 \\
\hline Soiled Utility Rooms & 14 & 6.4 \\
\hline Laundry & 4 & 1.8 \\
\hline Others & 5 & 2.3 \\
\hline \multicolumn{3}{|c|}{ 7-Participants received hepatitis B vaccine } \\
\hline \begin{tabular}{l|l} 
Yes \\
\end{tabular} & 197 & 89.5 \\
\hline No & 23 & 10.5 \\
\hline \multicolumn{3}{|l|}{ 8-Doses of hepatitis B vaccine } \\
\hline $\begin{array}{l} \\
0\end{array}$ & 23 & 10.5 \\
\hline 1 & 8 & 3.6 \\
\hline 2.00 & 30 & 13.6 \\
\hline 3.00 & 139 & 63.2 \\
\hline 4.00 & 20 & 9.1 \\
\hline
\end{tabular}

$\left.{ }^{*}\right)$ This percentage is out of $45.9 \%$

The table shows that, regarding numbers of completed reports about injuries, (66.8\%) of participants admitted that they were exposed to injuries by sharp objects, and (76.2\%) of them had not reported these injuries. Only $(19.7 \%)$ of them had completed one report about these injuries and (3.04\%) of them had completed two reports about SI as opposed to only $(1.06 \%)$ of them had completed three and more reports of these SI.

Regarding the reasons behind not reporting the contaminated injuries, (50.9\%) of injured participants didn't report their 


\section{International Journal of Science and Research (IJSR) \\ ISSN (Online): 2319-7064 \\ Index Copernicus Value (2013): 6.14 | Impact Factor (2014): 5.611}

injuries because they didn't know the reporting procedure; (20.5\%) didn't report their injuries because they considered reporting of these injuries unimportant. Fear to be blamed or get in trouble was another reason for not reporting the injuries.(6.3\%) of injured participants reported it. Confidentially about these injuries was another reason behind not reporting injuries. Only (1.8\%) cited it as a reason.

Regarding availability of protocol/ procedure for reporting the injuries, (45.9\%) said that the hospital had a procedure/protocol for reporting exposure as opposed to (31.4\%) who reported that the hospitals hadn't a procedure/protocol for reporting exposure. In contrast, (22.7\%) of participants didn't know if hospital had a procedure or protocol. Out of $(45.9 \%)$ who knew of the availability of this protocol, (38.6\%) of them were familiar with how to report these exposures as opposed to (61.4\%) who were not familiar with how to report these exposures.

Regarding receiving care after exposure to injuries, (28.6\%) of injured participants didn't receive care, as opposed to (26.5\%) who received care in emergency room while (23.1\%) received care in the infection control unit, and (1.4\%) received care in outpatient clinics.

Concerning distribution of participants according to where the sharp containers were placed in hospital, (40\%) of participants said that the sharp containers were placed in the procedure room while (40.3\%) reported that they were placed in medication carts.

Pertaining to hepatitis $\mathrm{B}$ vaccine, the table shows that (89.5\%) received hepatitis B vaccine as opposed to (10.5\%) who didn't take it. Concerning number of hepatitis B vaccine doses,(63.2\%) took three doses of hepatitis B vaccine, $(9.1 \%)$ took the poster doses in addition to these three doses, and (3.6\%) received one dose of vaccine.

\section{Discussion}

Prevalence of sharp injuries (SI) and needle stick injuries (NSI) in comparison with other studies

The results (Figure 1) showed that more than two thirds (66.8\%) of participants were injured by sharp objects in the past 12 months. This finding is similar to the finding of study done in Turkey by ${ }^{23}$. In that study, it was found that (68.4\%) of participants were exposed to SI in the past 12 months. Another study, done in United Arab Emirates indicated that the prevalence of SI was $(20.1 \%)^{24}$.

Regarding NSI from SI, Figure (1) showed that less than half of the participants (46.4\%) were exposed to NSI. NSI represented (69.4\%) of all SI in past 12 months. Comparison of the prevalence of NSI among nurses between developing and developed countries
Table 13: Comparison of prevalence of NSI between developed and developing countries:

\begin{tabular}{|c|c|c|}
\hline Author / date & Country & Prevalence of NSI \\
\hline \multicolumn{3}{|c|}{ Developed countries } \\
\hline Smith and Leggat /2005 & Australia & $13.9 \%$ \\
\hline Yao et al /2010 & China & $26.05 \%$ \\
\hline \multicolumn{2}{|c|}{ Developing countries } \\
\hline Jahan /2005 & Saudi Arabia & $66 \%$ \\
\hline Askarian et al /2007 & Iran & $49.6 \%$ \\
\hline Smion /2008 & India & $55.5 \%$ \\
\hline Manzoor et al /2010 & Pakistan & $71.9 \%$ \\
\hline
\end{tabular}

The prevalence of NSI in developed countries was lower than in developing countries. The prevalence of NSI in the current study was (46.4\%) and it was close to developing countries as Palestine is one of these countries. As shown, the prevalence of NSI in the current study was high. This might be due to a problem in the health system such as lack of knowledge about the dangerous effect of NSI, haste, reluctance, inadequate number of nurses, insufficient training of nurses on dealing with needles to prevent injuries and shortage of the numbers of sharp containers to dispose of the used needles in these sharp containers, in addition to the recapping of the used needles, and insufficient knowledge about dealing with needles. Pertaining to the numbers of injuries that happened in the past 12 months, table (1) showed that $(61.8 \%)$ of participants were exposed once to NSI in the past 12 months. It also showed that (53\% ) of participants were exposed once to SI in the past 12 months. This finding was in agreement with a study done in Jordan that found that more than half of participants were exposed to SI at least once in the past 12 months ${ }^{25}$. Another study found that (28.1\%) of participants had (1-2) injuries and $(34.1 \%)$ had (3-6) injuries ${ }^{26}$.

\section{Causes of sharp injuries in comparison with other studies}

Regarding the causes of sharp injuries, Figure (3) showed that most of injuries occurred during recapping of needle. They represented (20.2\%) of all SI in the past 12 months inspite of CDC's advice not to recap the needle to prevent of NSI. This finding is different from other findings. Manzoor et al.(2010) reported that the recapping of the needle after use represented (31.5\%) of all SI. In contrast, Lukianskyte, Gataeva and Radziunaite.(2011) reported that the recapping of needles represented (51.46\%). In addition, Ebrahim and Khosrav.(2007) found that (51.8\%) of all injuries occurred while recapping used needle and before disposing of it into sharp containers. On the other hand AlDabbas and Abu-Rmeileh, (2012) conducted a study among doctors and found that wound suturing represented (33.5\%) of all SI, the highest of all injuries. Akgur and Dal. (2012) showed that (70.9\%) of all injuries occurred during drug administration as opposed to (7.7\%) in the current study.

\section{Measures taken in hospitals regarding infection control (precautions and post exposure)in comparison with other studies: \\ Exposure of nurses to SI/NSI and exposure to blood or body fluid of patients should be reported in order to take an appropriate procedure or precaution and appropriate post- exposure treatment if it was recommended ${ }^{16}$. In spite of the}




\section{International Journal of Science and Research (IJSR) \\ ISSN (Online): 2319-7064 \\ Index Copernicus Value (2013): 6.14 | Impact Factor (2014): 5.611}

importance of reporting injuries, many of injuries was underreported. Table (12) showed that (76.2\%) of injuries had not been reported. The main reason was that the participants didn't know the reporting procedure. This represented (50.9\%) of all causes of not reporting the injuries. A study done in Turkey reported that (39.5\%) of injuries had not been reported because participants were too busy $^{\mathbf{1 6}}$. Another study found that (45.9\%) of injuries had not been reported by the participants and the main reason was that the participants didn't think it was important to report them $^{12}$. A third study found that $(69.1 \%)$ of participants failed to report the injuries ${ }^{30}$. On the other hand, other studies had higher percentage of injuries that hadn't been reported. For example, in one study (76\%) of participants hadn't reported the injuries and the main reason was that the participants did not consider SI serious ${ }^{12}$. Another study found that $(84.5 \%)$ of injuries hadn't been reported and the main reason was that the participants didn't know that injuries should be reported ${ }^{26}$. Another study found that (92\%) of participants hadn't reported the injuries. The main reason was that participants (students) didn't think it was important to report them ${ }^{13}$.

Sharp injuries and needle stick injuries may increase the risk of transmission of blood-borne pathogen (BBP) especially hepatitis C, hepatitis B and HIV which have bad consequences such as disabilities, and long term illnesses that may lead to death ${ }^{2}$. Therefore, it is very important to follow up the injured participants and give them postexposure prophylaxis and hepatitis B vaccine. Table (2) showed that $(28.6 \%)$ of the injured participants hadn't received care. Vaz et al. (2010) reported that (40.5\%) of participants did not receive any medical attention. Regarding hepatitis B vaccine, table (2) revealed that the vast majority of participants (89.5\%) had taken hepatitis B vaccine. This high percentage might be due to the requirement of $\mathrm{MOH}$. Concerning the numbers of doses of hepatitis $b$ vaccine, table (2) showed that (63.2\%) of participants admitted they had taken vaccine (3 doses of hepatitis B vaccine), while only (9.1\%) of them had taken 3 doses of hepatitis B vaccine and poster dose. In a study done in Syria, Yacoub et al.(2010) reported that (8.6\%) of participants had never been vaccinated against hepatitis B vaccine and (68.6\%) had taken complete doses of vaccine. In one study done in Thailand Honda et al.(2011) found that (70\%) of the participants had taken all doses of hepatitis B vaccine.In another study done in Turkey, Iramk (2008) study found that $(81.8 \%)$ of participants were immunized against hepatitis B. In a third study in Abha, Saudi Arabia done by Mahfouz et al, (2009) found that (82.4\%) of participants had received at least 3 doses of hepatitis $B$ vaccine. In a study in Cyprus, Akgur and Dal (2012) reported that (92\%) of participants had taken hepatitis B vaccine.

\section{References}

[1] Center of Disease Prevention and Control (CDC).(2012) . Glossary of Terms .Atlanta , USA.
[2] World health organization .(2002). The World Health Report 2002 Reducing Risks, Promoting Healthy Life. Geneva, Switzerland. pp.218

[3] World health organization (WHO) .(2012). Healthcare associated infection. fact sheet . Geneva , Switzerland. Retrieved from : www.who.int/gpsc

[4] World health organization (WHO).(2009).Guidelines on hand hygiene in health care :a summary. Geneva Switzerland ,pp.52. Retrieved from: whqlibdoc.who.int

[5] World health organization (WHO).(2001). Infections and infectious disease. A manual for nurses and midwives in the WHO European Region , pp .282. Retrieved fom: www.euro.who.int

[6] Goniewicz, M., Włoszczak-Szubzda, A., Niemcewicz, M., Witt, M., Marciniak-Niemcewicz, A., Jarosz, MJ.(2012). Injuries caused by sharp instruments among healthcare workers--international and Polish perspectives. Annals of Agricultural Environmental Medicine, 19 , pp.523-527.

[7] Elizabeth, A., Bolyard, RN., Ofelia, C., Walter, W., Michele, L. Craig, N., Scott, D.(1998). Guidelines for infection control in health care personnel. Infection Control and Hospital Epidemiology, 19,pp.445.

[8] Center of Disease Prevention and Control CDC .(2007). Guideline for Isolation Precautions: Preventing Transmission of Infectious Agents in Healthcare Settings . US .136p. Retrieved from: www.cdc.gov/hicpac/pdf/isolation/isolation2007.pdf

[9] Center of Disease Prevention and Control (CDC).(2013). Blood/Body Fluid Exposure Option.US. Retrieved fromhttp://www.cdc.gov/nhsn/PDFs/HPSmanual/exposure/3-HPS-Exposure-options.pdf

[10] National Health and Medical Research Council (NHMRA). (2010).Clinical educator guide for prevention and control of infection in healthcare .Australian Commission on Safety and Quality in control. Austeralia ,pp.15. Retreieved from: http://www.nhmrc.gov.au/_files_nhmrc/publications/at tachments/cd33_icg_clinical_ed_guide_

[11] National Institute for Occupational Safety and Health (NIOSH). (2011).Centre of Disease Prevention and Control (CDC).Sharps Injuries. Atlanta. Retrieved from www.cdc.gov/niosh/stopsticks/sharpsinjuries.htm

[12] Honda,M,, Chompikul, J., Rattanapan, C., Wood, G, Klungboonkrong, S .(2011). Sharps injuries among nurses in a Thai regional hospital: prevalence and risk factors. International Journal of Occupational and Environmental Medicine, pp.215-223.

[13] Lukianskyte, R., Gataeva, J., Radziunaite, L.(2011). Needle sticks and sharps injuries experienced by staff nurses and nursing students and their prevention. International Journal of Infection Control , 8 ,pp.1-9.

[14] Smith, DR., Leggat, PA.(2005). Needlestick and sharps injuries among nursing students. Journal of Advanced Nursing , 51,pp.449-455.

[15] Centers for Disease Control and Prevention (CDC). (2001).Department of Health and Human Services . Updated U.S. Public Health Service Guidelines for the Management of Occupational Exposures to HIV and Recommendations for Post exposure Morbidity 
and mortality weekly report . U.S, Atlanta : published by the Epidemiology Program Office,17p. Retrieved from: www.cdc.gov/mmwr/preview/mmwrhtml/rr5409a1.ht $\mathrm{m}$

[16] Irmak, Z .(2008). Needlestick and sharps injury among nurses at a state hospital in Turkey. Australian Journal of Advanced Nursing , 30 .pp .4855.

[17] World Health Organization (WHO).(2007) .Standard precautions in health care aide-memoire. Geneva .Switzerland .Retrieved from www.who.int/csr/resources/.../standardprecautions/en/

[18] Occupational Safety and Health Administration (OSHA) .(2011) . Protecting Yourself When Handling Contaminated Sharps . Fact sheet. Retrieved from: https://www.osha.gov/OshDoc/data_BloodborneFacts/ bbfact02.pd

[19] National Institute for Occupational Safety and Health NIOSH (1998).CDC selection, evaluation and using of sharps disposal containers .US department of human health and service .Atlanta . Retrieved from: www.cdc.gov/niosh/pdfs/97-111.pd

[20] Aiken,LH., Sloane, DM., Klocinski, JL.(1997). Hospital nurses' occupational exposure to blood: prospective, retrospective, and institutional reports. American journal for public health,87,pp.103-107.

[21] Park, S., Jeong, I., Huh, J., Yoon, Y., Lee, S., Choi, C.(2008). Needlestick and sharps injuries in a tertiary hospital in the Republic of Korea.Amrican Journal of Infection Control ,36,pp.439-44

[22] Efstathiou, G., Papastavrou, E., Raftopoulos, V., Merkouris, A.(2011).Factors influencing nurses' compliance with Standard Precautions in order to avoid occupational exposure to microorganisms: A focus group study.BMC Nursing,1,PP.10.

[23] IIhan, M., Durukan, E., Turkcuoglu, S., Aygun, R.(2006).Long working hours increase the risk of sharp and needlestick injury in nurses: the need for new policy implication. Journal of Advanced Nursing,56,pp.563-568

[24] Sreedharan, J., Muttappillymyalil, J., Venkatramana, $M$.(2011). Knowledge about standard precautions among university hospital nurses in the United Arab Emirates. Eastern Mediterranean Health Journal. 17 ,pp.331-334

[25] Hassan, Z., Wahsheh, M.(2007). Occupational Exposure to Sharp Injuries Among Jordanian Health Care Workers, Infectious Diseases in Clinical Practice,17,pp.169-174

[26] Akgur, M., Dal, U.(2012). The prevalence of needle stick and sharps injuries in nurses in North Cyprus. Pakistan Journal of Medical Science, 28,pp.437-440.

[27] Manzoor, I., Daud, S., Hashmi,NR., Sardar, H., Babar, MS., Rahman, A., Mali,k M . (2010).Needle stick injuries in nurses at a tertiary health care facility .Journal of Ayub Medical Collage Abbottabad, 22 ,pp.174-178.

[28] Ebrahim, H., Khosrav, A. (2007). Needlestick Injuries among Nurses. Journal of Research in Health Sciences,7,pp.56-62.
[29] Al-Dabbas, M., Abu-Rmeileh, NM .(2012) .Needlestick injury among interns and medical students in the Occupied Palestinian Territory. Eastern Mediterranean Health Journal, 18,pp.700-706

[30] Ayranci, U., Kosgeroglu, N .(2004). Needlestick and sharps injuries among nurses in the healthcare sector in a city of western Turkey. Journal of Hospital Infection, 58,pp.216-223.

[31] Vaz, k., McGrowder, D., Alexander-Lindo, R., Gordon, L., Brown, P., Irving, R .(2010) . Knowledge, awareness and compliance with universal precautions among health care workers at the University Hospital of the West Indies, Jamaica. International Journal Occupational and Environmental Medicine , 1,pp.171-181.

[32] Yacoub, R., Al Ali, R., Moukeh, G., Lahdo, A., Mouhammad, Y., Nasser, M.(2010). Hepatitis B vaccination status and needlestick injuries among healthcare workers in Syria. Journal of Glob Infectious Disease ,pp.28-34.

[33] Mahfouz, A., Abdelmoneim, I., Khan, M., Daffalla, A., Diab, M., Shaban, H., Al Amri, H.(2009). Injection safety at primary health care level in south-western Saudi Arabia . Eastern Mediterranean Health Journal, 15,pp.443-450 